\title{
Исследование кремния, легированного ионами цинка и отожженного в кислороде
}

\author{
(C) В.В. Привезенцев ${ }^{1}$, Е.П. Кириленко ${ }^{2}$, А.Н. Горячев ${ }^{2}$, А.А. Батраков ${ }^{3}$ \\ ${ }^{1}$ Физико-технологический институт Российской академии наук, \\ 117218 Москва, Россия \\ ${ }^{2}$ Национальный исследовательский университет „МИЭТ“, \\ 124458 Москва, Зеленоград, Россия \\ ${ }^{3}$ Национальный исследовательский университет „МЭИ“, \\ 111250 Москва, Россия \\ E-mail: v.privezentsev@mail.ru
}

(Получена 19 апреля 2016 г. Принята к печати 24 июня 2016 г.)

\begin{abstract}
Представлены результаты исследования приповерхностного слоя кремния и формирования преципитатов в образцах $\mathrm{CZ} n$ - $\mathrm{Si}(100)$, имплантированного ионами ${ }^{64} \mathrm{Zn}^{+}$с дозой $5 \cdot 10^{16} \mathrm{~cm}^{-2}$ с энергией 50 кэВ при комнатной температуре с последующим окислением при температурах от 400 до $900^{\circ} \mathrm{C}$. Визуализация поверхности проведена с помощью электронного микроскопа, а приповерхностного слоя с профилированием по глубине с помощью картирования элементов методом оже-электронной спектрокопии. Анализ распределения примесных ионов в кремнии проводился на времяпролетном вторично-ионном масс-спектрометре. Методом рентгеновской фотоэлектронной спектроскопии исследовано химическое состояние атомов матрицы кремния и примесных атомов цинка и кислорода, а также уточнен фазовый состав имплантированного и отожженных образцов.

После имплантации Zn наблюдаются два максимума его концентрации: на поверхности пластины и на глубине 70 нм, при этом на поверхности и в приповерхностном слое происходит образование наночастиц фазы металлического $\mathrm{Zn}$ и фазы $\mathrm{ZnO}$ с размером порядка 10 нм. После отжига в кислороде в $\mathrm{Si}$ вблизи поверхности обнаружена фаза $\mathrm{ZnO} \cdot \mathrm{Zn}_{2} \mathrm{SiO}_{4}$, а на глубине 50 нм фаза $\mathrm{Zn} \cdot \mathrm{ZnO}$.
\end{abstract}

DOI: $10.21883 /$ FTP.2017.02.44102.8285

\section{1. Введение}

В последнее время широко исследуются свойства наночастиц (НЧ) металлов в различных матрицах, поскольку такие материалы могут быть использованы в современных устройствах электроники [1]. Для формирования таких НЧ наиболее подходит метод ионного легирования, поскольку кроме важных особенностей этого метода (чистоты, мобильности и др.), главное его достоинство состоит в том, что можно получать концентрации имплантированных примесей металлов гораздо больше предела их равновесной растворимости в подложке. Температурная обработка используется не только для отжига радиационных дефектов, но и для зарождения и роста металлических НЧ [2]. Поэтому исследования подложек, имплантированных примесями металлов, в частности, цинком, становятся очень важными и проводятся достаточно интенсивно [3-5].

Среди таких материалов матрицы с НЧ из $\mathrm{ZnO}$ играют особую роль, поскольку окись цинка является прямозонным материалом с шириной запрещенной зоны 3.37 эВ и имеет большую энергию связи электрона и дырки в экситоне 60 мэВ, которая позволяет получать УФ излучение с длиной волны $\lambda=370$ нм при температуре до $450^{\circ} \mathrm{C}$. Поэтому матрицы с НЧ из $\mathrm{ZnO}$ могут найти широкое применение в таких современных оптоэлектронных устройствах, как светодиоды и УФ лазеры [6]. Также перспективно их применение в солнечных элементах на основе сенсибилизированных полимерных материалов [7] и электролюминесцентных дисплеях [8], сенсорных газовых устройствах [9], элементах памяти нового поколения (мемристорах) [9], элементах спинтроники [10] и пьезоэлектроники [11], а также медицине [12] и биологии [13].

НЧ из $\mathrm{ZnO}$ в кремниевой матрице и других матрицах могут быть сформированы термообработкой в нейтрально-окислительной среде подложек, содержащих металлический Zn. Такие структуры могут быть получены методом легирования ионами $\mathrm{Zn}[14,15]$. Получаемые при этом концентрации цинка в кремнии могут быть гораздо большего значения их предельной равновесной растворимости в кремнии, которая составляет $N_{\mathrm{Zn}}^{\lim }=6 \cdot 10^{16} \mathrm{~cm}^{-3}$ [16] при температуре диффузии $1250^{\circ} \mathrm{C}$.

В работе представлены результаты формирования НЧ в $\mathrm{Si}$, легированном ионами $\mathrm{Zn}$ и отожженном в кислороде при повышенных температурах.

\section{2. Образцы и методики эксперимента}

Для исследования были использованы выращенные по Чохральскому пластины монокристаллического кремния $n$-типа толщиной 350 мкм с ориентацией (100) и концентрацией электронов $n_{0}=5 \cdot 10^{15} \mathrm{~cm}^{-3}$. Пластины были имплантированы ионами цинка ${ }^{64} \mathrm{Zn}^{+}$с дозой $D=5 \cdot 10^{16} \mathrm{~cm}^{-2}$ и энергией $E=50$ кэВ при комнатной температуре. Плотность ионного тока $\left(j \leq 0.5\right.$ мкА $\left./ \mathrm{cm}^{2}\right)$ была такова, что перегрев подложки, по сравнению 
с комнатной температурой, не превышал $50^{\circ} \mathrm{C}$. Затем пластины были последовательно изохронно в течение 1 ч отожжены при температурах от 400 до $900^{\circ} \mathrm{C}$ с шагом $100^{\circ} \mathrm{C}$ с целью определения температуры образования фазы ZnO. Оказалось, что для формирования фазы окиси цинка при выбранных нами условиях легирования ионами цинка (энергия и доза) и изохронном в течение 1 ч отжиге в кислороде оптимальным является диапазон температур $700-800^{\circ} \mathrm{C}$.

Топография поверхности образцов была исследована с помощью растрового электронного микроскопа (РЭМ) Auriga 39-52 (ZEISS) в режиме вторичных электронов (ВЭ). Анализ распределения примесей $\mathrm{Zn}, \mathrm{O}$ и других ионов в кремнии проводился на времяпролетном вторично-ионном масс-спектрометре (ВП ВИМС) TOF.SIMS-5 (IonTOF GmbH). Этот анализ проходил в следующих условиях: травление кратера проводилось ионами цезия $\mathrm{Cs}^{+}$(для анализа ионов ${ }^{28} \mathrm{Si}^{-}$, $\left.{ }^{16} \mathrm{O}^{-}, \mathrm{ZnO}^{-}, \mathrm{SiO}^{-}, \mathrm{SiO}_{2}^{-}\right)$и ионами кислорода $\mathrm{O}_{2}^{+}$ (для анализа ионов ${ }^{28} \mathrm{Si}^{+},{ }^{64} \mathrm{Zn}^{+}$) с энергией 1 кэВ, размеры растра травления были $300 \times 300$ мкм. Параметры анализирующего ионного пучка: ионы висмута $\mathrm{Bi}$ с энергией 30 кэВ, ток ионного Ві пучка висмута $i=1.2$ нА, диаметр ионного пучка около $131 \mathrm{нм}$, растр анализа $100 \times 100$ мкм. Визуализация и идентификация приципитатов с профилированием по глубине проводилась на сканирующем оже-электронном спектрометpe (ОЭС) PHI-670xi (Physical Electronics). Электронная пушка с термополевым эмиссионным катодом (катод Шоттки) имела следующие параметры: ускоряющее напряжение 5 кВ, при регистрации спектров первичный ток был равен 10 нА, при получении изображений во ВЭ и в оже-электронах (картирование) он был равен 1 нА. При этом диаметр электронного пучка составлял 50-100 нм. Химическое состояние элементов матрицы кремния, цинка и кислорода исследовалось методом рентгеновской фотоэлектронной спектроскопии (РФЭС) с помощью модуля на базе платформы из Nanofab 25 (NT-MDT). Энергетическое разрешение спектрометра SPECS Phoibos 225 по линии $\mathrm{Ag}^{\circ} 3 d 5 / 2$ составляло 0.78 эВ для немонохроматического рентгеновского излучения $\mathrm{Mg}^{\circ} \mathrm{K}_{\alpha}$.

\section{3. Результаты и их обсуждение}

После имплантации на РЭМ-ВЭ изображении наблюдается слабый топологический контраст (темные области на сером фоне), связанный с наличием вблизи поверхности образца преципитатов. По-видимому, это загрязнения углеродом. На рис. 1 приведено РЭМ-ВЭ изображение поверхности кремниевой подложки, относящееся уже к отожженному в кислороде образцу при $700^{\circ} \mathrm{C}$. На нем видно, что после отжига на поверхности кремния образовалась НЧ с поперечным размером от 10 до 50 нм. На РЭМ-ВЭ изображении НЧ имеют более светлый тон по сравнению с фоном от кремния. Очевидно, что эти НЧ содержат цинк. Это могут быть как НЧ самого металлического $\mathrm{Zn}$, так и его соединений типа $\mathrm{ZnO}, \mathrm{ZnSiO}_{3}$ или $\mathrm{Zn}_{2} \mathrm{SiO}_{4}$. О фазовом составе приповерхностного слоя кремния как после имплантации, так и после отжига будет сказано более подробно далее.

На рис. 2 приведены профили ВП ВИМС кремниевой подложки. На рис. 2, а видно, что имплантированный

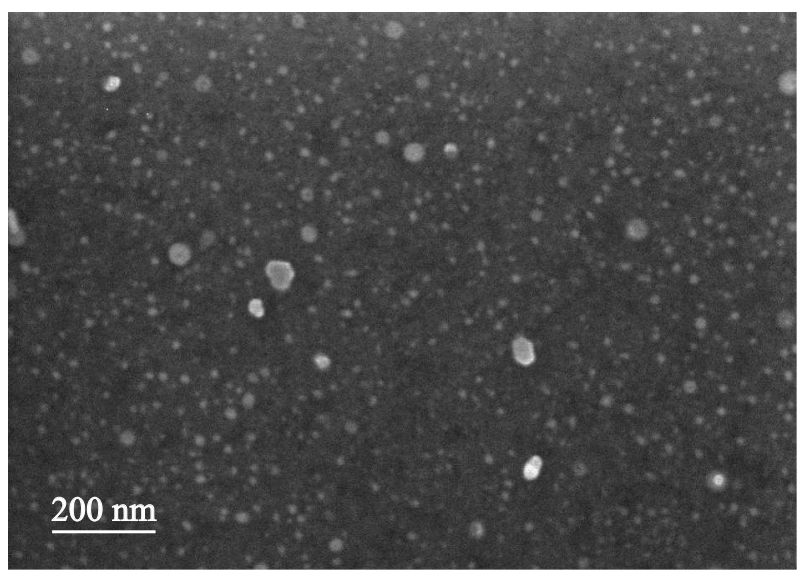

Рис. 1. РЭМ-ВЭ изображение поверхности кремния после отжига в кислороде при $700^{\circ} \mathrm{C}$ в течение 1 ч.

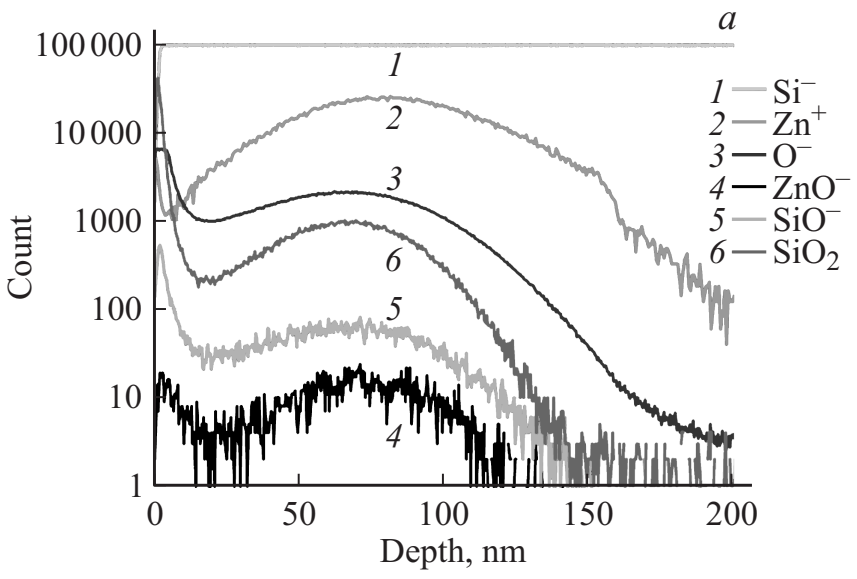

$b$

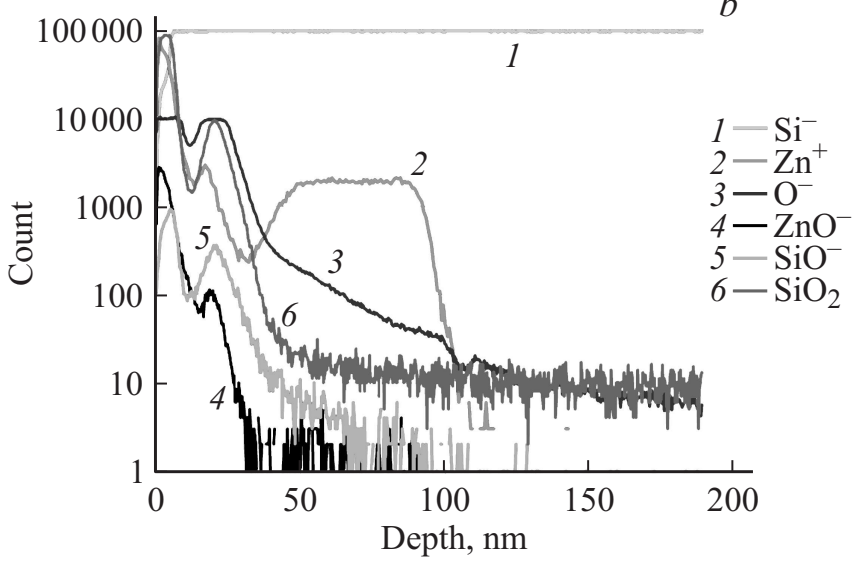

Рис. 2. TOF SIMS профили для образцов: имплантированного $(a)$ и отожженного в кислороде при $800^{\circ} \mathrm{C}(b)$. 
цинк распределен до глубины 200 нм, причем максимум его распределения находится на глубине 75 нм; на поверхности также находится небольшой его максимум. Профиль окиси цинка $\mathrm{ZnO}$ в общем повторяет профиль имплантированного цинка, но до глубины примерно 120 нм, причем его максимум расположен на глубине примерно 60 нм. Его образование мы связываем с наличием в кремнии, выращенном по Чохральскому, растворенного неактивного кислорода, содержание которого находится на уровне $10^{17}-10^{18} \mathrm{~cm}^{-3}$. Этот кислород вступает в реакцию с имплантированным цинком. Также c $\mathrm{Zn}$ может взаимодействовать кислород, увлеченный c поверхности образца в его глубь при имплантации цинка. Как видно из полученных данных на рис. 2, $a$, на поверхности образца после имплантации есть тонкий слой окиси кремния состава $\mathrm{SiO}_{x}$. Кроме того, во время имплантации кислород с поверхности может увлекаться ионами цинка в глубь подложки. Эти объясняется максимум концентрации ионов $\mathrm{O}^{-}, \mathrm{SiO}^{-}$и $\mathrm{SiO}_{2}^{-}$на грубине около $60 \mathrm{Hм}$, а также максимум распределения ионов $\mathrm{ZnO}^{-}$на этой же глубине.

На рис. 2, $b$ видно, что при отжиге в кислороде цинк и кислород в матрице кремния движутся к поверхности образца. В распределении цинка после отжига при $800^{\circ} \mathrm{C}$ в кислороде наблюдаются 3 максимума. Первый, самый большой по величине и узкий по протяженности, максимум расположен на поверхности кремния. Второй, величиной на 1.5 порядка меньше, - на глубине 20 нм. Третий максимум примерно той же величины, что и второй, но в виде широкого плато, - на глубине от 50 до 100 нм. При отжиге в кислороде на поверхности естественно растет слой оксида кремния, величины которого, согласно профилю (5), составляют около $10 \mathrm{Hм.}$ В этой области образуются оксидные соединения цинка, регистрируемые в виде ионов $\mathrm{ZnO}^{-}$(кривая 4), и кремния, регистрируемые в виде ионов $\mathrm{SiO}^{-}$(кривая 5) и $\mathrm{SiO}_{2}^{-}$(кривая 6). Все вышеперечисленные кривые повторяют форму профиля кислорода $\mathrm{O}^{-}$(кривая 3 ).

На рис. 3, а представлены ОЭС профили концентрации атомов матрицы $\mathrm{Si}$ и примесей после имплантации $\mathrm{Zn}$. Как видно из профиля 4 на рис. 3, $a$ максимум концентрации Zn после его имплантации находится на глубине примерно 80 нм, а на поверхности расположен слой окиси кремния толщиной до 20 нм (кривая 2). Распределение кислорода (кривая 1) имеет 3 максимума: первый (главный) — на поверхности, второй (средний по величине) - на глубине 17 нм, третий (наименьший) - на глубине 70 нм. Такое распределение кислорода мы связываем с увлечением кислорода цинком при имплантации последнего из поверхностной естественной пленки $\mathrm{SiO}_{2}$, толщина которой составляет 2-5 нм. После имплантации зафиксирован слой окисленного кремния $\mathrm{Si}(\mathrm{O})^{+}$толщиной 20 нм. На глубине 70 нм при максимуме распределения имплантированного цинка было получено изображение. Оказалось, что рельей поверхности неоднороден: на ней расположены полосы и бугорки шириной в пределах 70-100 нм и высотой около 10 нм.
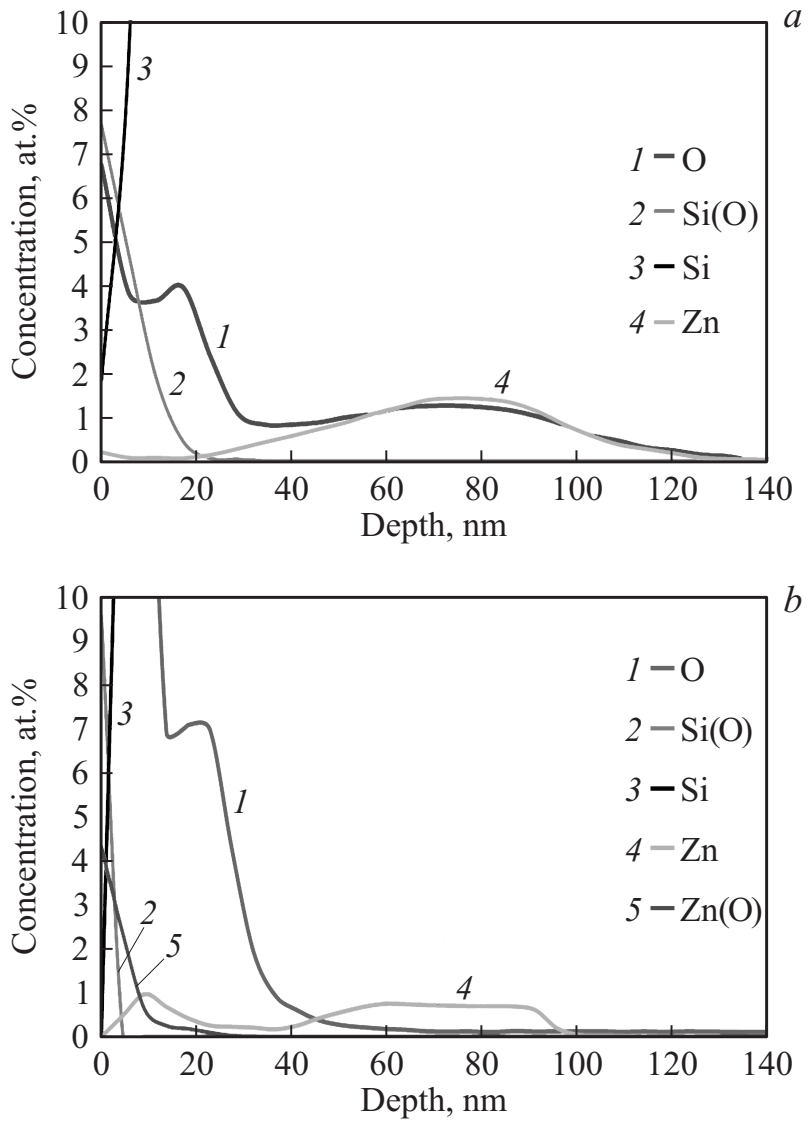

Рис. 3. ОЭС-профили для образцов: имплантированного $(a)$ и отожженного в кислороде при $800^{\circ} \mathrm{C}(b)$.

Как видно из ОЭС профиля 4 на рис. 3, $b$, после отжига в кислороде максимум концентрации цинка имеет 2 максимума: узкий на глубине 10 нм и несколько меньший по величине, но в виде плато на глубине 60-90нм. В отожженном образце появился профиль окиси цинка $\mathrm{ZnO}$, который имеет большой максимум $(4 \%)$ на поверхности и спадающий до глубины $30 \mathrm{Hм}$ „хвост“. Из анализа рис. $3, b$ также следует, что на поверхности расположен слой окиси кремния толщиной 5 нм (кривая 2). Распределение кислорода (кривая 1) имеет 2 максимума: первый - на поверхности, а второй - на глубине 20 нм.

Для отожженного образца также были рассчитаны дозы цинка по оже-профилям: суммарный полный флюенс в подложке $\mathrm{Zn} 3.92 \cdot 10^{15} \mathrm{~cm}^{-2}$, в том числе дозы окисленного цинка в форме $\mathrm{ZnO} 1.30 \cdot 10^{15} \mathrm{~cm}^{-2}$ и „неокисленного“ металлического цинка $2.62 \cdot 10^{15} \mathrm{~cm}^{-2}$.

На рис. 4 приведены оже-спектры для переходов $\mathrm{Zn}(\mathrm{LMM})$ и $\mathrm{Si}(\mathrm{LVV})$ в узком диапазоне энергий в четыpex точках на разной глубине. При сравнении положения четырех пиков $\mathrm{Zn}(\mathrm{LMM})$ и четырех пиков $\mathrm{Si}(\mathrm{LVV})$ видно, что на поверхности и в приповерхностном слое положение всех пиков от глубины 17 нм до поверхности (0 нм) сдвинуто в сторону меньших энергий и происходит изменение формы самих оже-пиков. Сдвиг 
$\operatorname{Zn}(\mathrm{LMM})$ оже-пика составляет 5 эВ, а для оже-пика $\mathrm{Si}(\mathrm{LVV})$ наблюдается не только энергетический сдвиг в 11 эВ, но и значительное изменение формы самого пика. Сдвиг и изменение формы пиков свидетельствуют как о положительном заряде этих атомов, так и о связи как атомов $\mathrm{Si}$, так и атомов $\mathrm{Zn}$ с атомами $\mathrm{O}$ с образованием их оксидных соединений на поверхности и вблизи нее.

На рис. 5 приведены изображения приповерхностной области отожженного при $700^{\circ} \mathrm{C}$ образца на глубине 5 нм в режиме РЭМ-ВЭ $(a)$ и картирование той же поверхности в оже-электронах для $\mathrm{Zn}(b)$. Из рисунка $(a)$ следует, что состав поверхности образца неоднороден: видны кластеры с размером 50-100 нм. Некоторые из этих кластеров со светлым контрастом могут содержать $\mathrm{Zn}$, поскольку известно, что более светлый тон дают элементы с большей массой, чем элементы основной матрицы Si. На рисунке $(b)$ с картированием в ожеэлектронах для $\mathrm{Zn}$ видно, что светлые участки РЭМ-ВЭ изображении соответствуют преципитатам фазы, содержащей Zn.

На рис. 6, $a$ представлены спектры РФЭС для состояния $\mathrm{Zn} 2 p_{3 / 2}$ для образца отожженного при температуре $800^{\circ} \mathrm{C}$. На поверхности (кривая 1 ) для состоя-
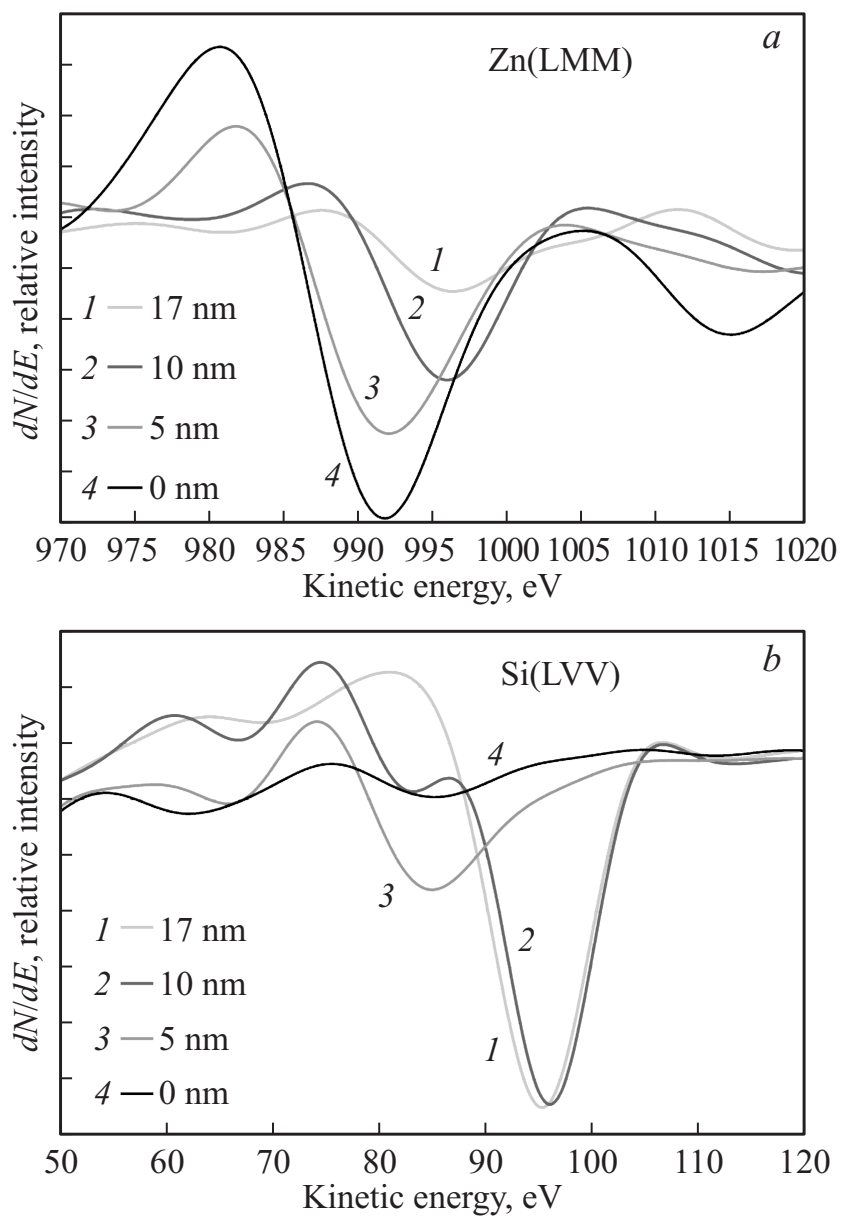

Рис. 4. Оже-спектры для $\mathrm{Zn}(\mathrm{LMM})$ и $\mathrm{Si}(\mathrm{LVV})$ в четырех точках. Глубина поверхности: $1-17,2-10,3-5,4-0$ нм (поверхность).

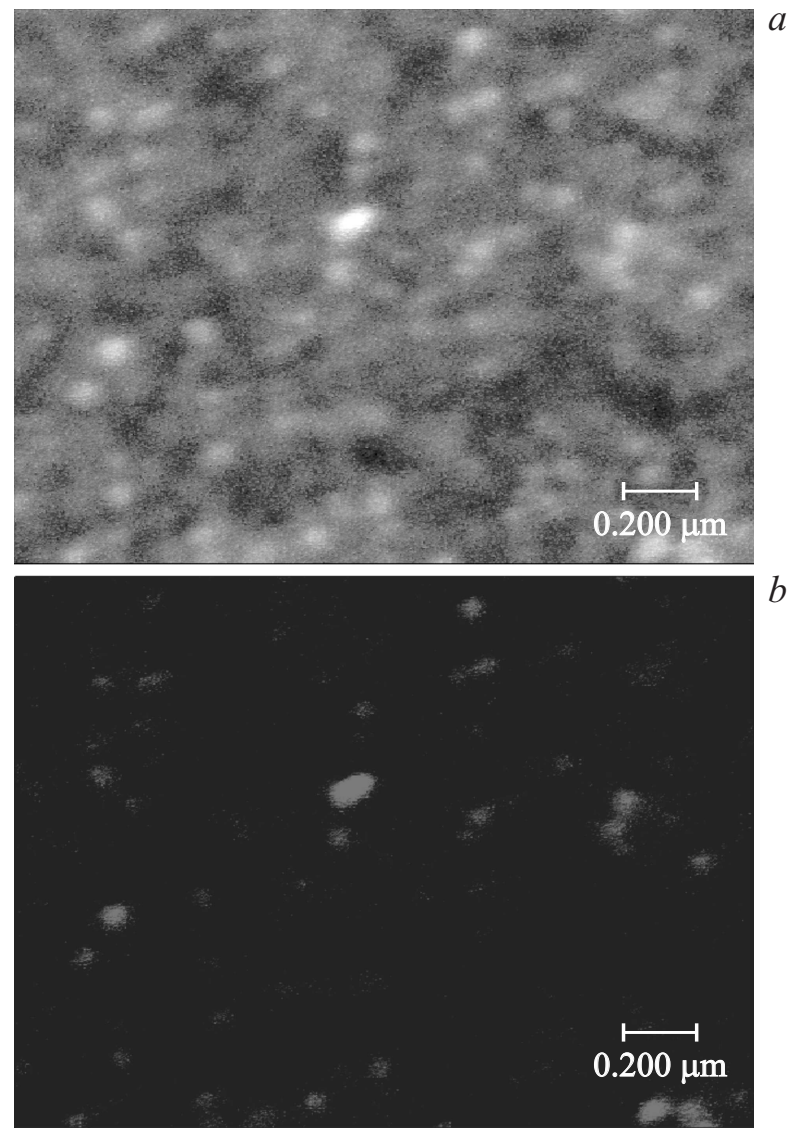

Рис. 5. Изображения области отожженного образца на глубине 5 нм: РЭМ-ВЭ $(a)$ и картирование той же области в ожеэлектронах для $\mathrm{Zn}(b)$.

ния $\mathrm{Zn} 2 p_{3 / 2}$ энергия связи составляет 1025.0 эВ, что соответствует двум формам окисных соединений $\mathrm{Zn}$, а именно $\mathrm{ZnO}$ и $\mathrm{Zn}_{2} \mathrm{SiO}_{4}$ [17]. На глубине 40 нм (кривая 5) для состояния $\mathrm{ZnO} 2 P_{3 / 2}$ имеет место энергетический сдвиг до значения 1024.8 эВ. Последняя величина соответствует двум формам химического состояния $\mathrm{Zn}$, a именно металлической фазе $\mathrm{Zn}$ и оксидной фазе $\mathrm{ZnO}$ [17].

На рис. 6, $b$ представлены спектры РФЭС состояния для $\mathrm{Si} 2 p_{3 / 2}$ для образца отожженного при температуре $800^{\circ} \mathrm{C}$. На поверхности (спектр 1) для состояния $\mathrm{Si} 2 p_{3 / 2}$ энергия связи представляет кривую с максимумом 104.0 эВ, что соответствует оксидной фазе кремния состава $\mathrm{SiOSiO}_{2}$. По мере углубления этот максимум уменьшается по величине, но появляется другой максимум с энергией 100.0 эВ (спектры 3-5), соответствующие нейтральной фазе $\mathrm{Si}^{\circ}$ [17]. Из этих спектров следует, что на поверхности находится пленка окисла кремния толщиной до 40 нм.

Эволюция HЧ Zn при отжиге в кислороде может быть объяснена температурной зависимостью диффузионной длины $L$ для молекул $\mathrm{O}_{2}$ в $\mathrm{Si}$ и перемещением атомов цинка к поверхности образца. Согласно формуле $L=2 \sqrt{D t}$, где $D-$ коэффициент диффузии, $t-$ время 

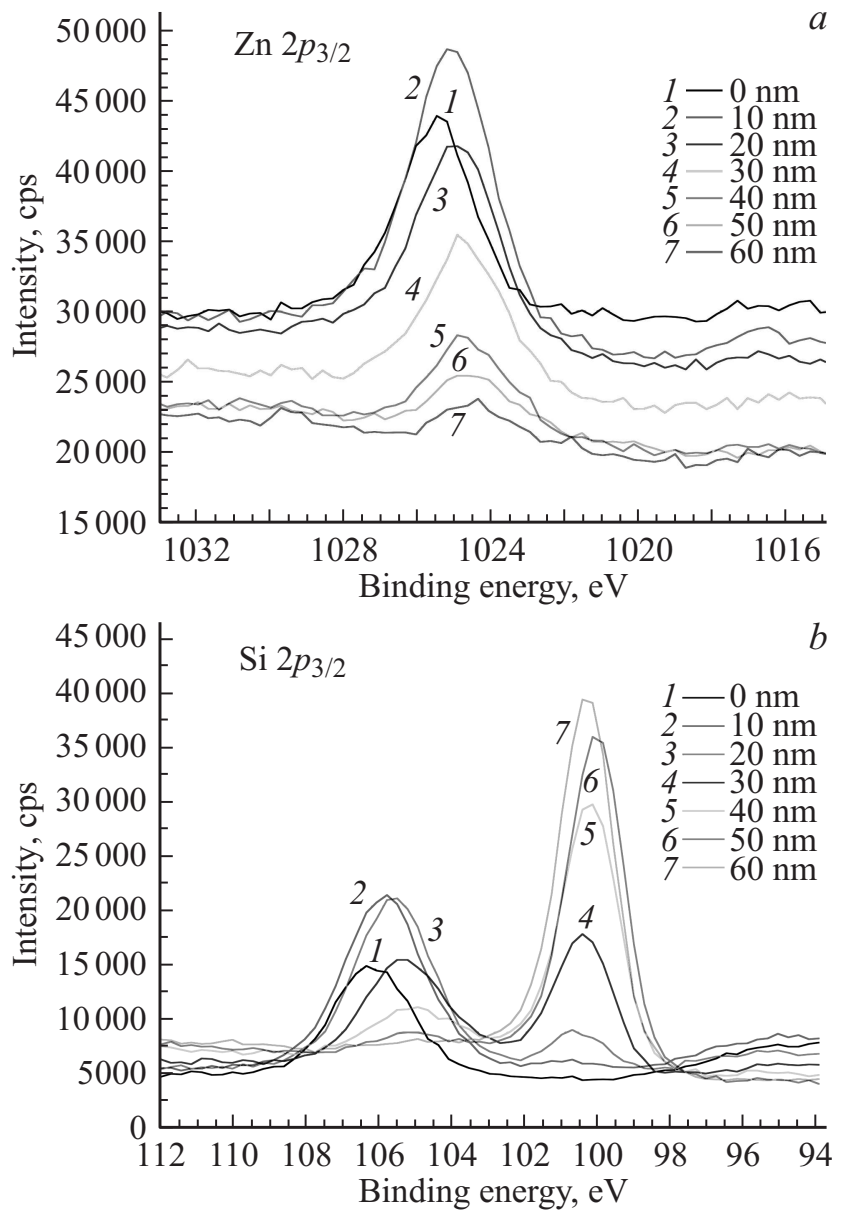

Рис. 6. РФЭС спектры для образца, отожженного при $800^{\circ} \mathrm{C}$, для $\mathrm{Zn}(a)$ и для $\mathrm{Si}(b)$.

отжига (здесь $D=D_{0} \exp (-E / k T)$, где $D_{0}=0.025 \mathrm{~cm}^{2} / \mathrm{c}$ и $E=2.43$ эВ [18]), величина $L$ при температурах отжига 600 и $800^{\circ} \mathrm{C}$ в течение 1 ч составляет соответственно 20 и 380 нм. Поскольку максимум концентрации Zn расположен на глубине $40 \mathrm{Hм}$, во время отжига при температурах ниже $700^{\circ} \mathrm{C}$ невозможно окисление НЧ металлического Zn. При более высокой температуре отжига молекулы $\mathrm{O}_{2}$ могут продиффундировать в глубь образца и встретиться с атомами $\mathrm{Zn}$, тем более что при этом атомы $\mathrm{Zn}$ начинают перемещаться им навстречу к поверхности образца. Результатом этого является окисления НЧ $\mathrm{Zn}$ и образование НЧ состава $\mathrm{ZnO} \cdot \mathrm{Zn}_{2} \mathrm{SiO}_{4}$ вблизи поверхности образца и состава $\mathrm{Zn} \cdot \mathrm{ZnO}$ в его глубине. Таким образом, при отжиге в кислороде Zn перемещается к поверхности и частично окисляется, а кислород, проникший в приповерхностный слой из окружающей атмосферы, окисляет не только $\mathrm{Si}$, но и $\mathrm{Zn}$.

\section{4. Заключение}

1) Распределение концентрации имплантированного $\mathrm{Zn}$ имеет два максимума: на поверхности пластины и на грубине 70 нм.
2) Имплантация $\mathrm{Zn}$ приводит к появлению на поверхности пластины и в приповерхностном слое двух фаз: $\mathrm{Zn}$ и $\mathrm{ZnO}$.

3) После отжига в $\mathrm{O}_{2}$ на поверхности образца вырастает слой оксида кремния толщиной 40 нм.

4) НЧ сложной фазы $\mathrm{ZnO} \cdot \mathrm{Zn}_{2} \mathrm{SiO}_{4}$ с поперечным размером порядка 10 нм образуются на поверхности и в приповерхностной области на глубине 5 нм после отжига в $\mathrm{O}_{2}$.

5) Отжиг $\mathrm{O}_{2}$ приводит к образованию на глубине 50 нм сложной фазы $\mathrm{Zn} \cdot \mathrm{ZnO}$.

\section{Список литературы}

[1] Metal Oxide Nanostructures and Their Applications, ed. by A. Umar, Y.-B. Hahn (Chonbuk National University, S. Korea, 2010).

[2] C. Jiang, X. Sun, G. Lo et al. Appl. Phys. Lett. 90, 263501 (2007).

[3] O. Eryu, K. Murakami, K. Takita, K. Masuda. Nucl. Instr. Meth. B, 33, 665 (1988).

[4] G. Zollo, M. Kalitzova, D. Manno, G. Vitali. J. Phys. D: Appl. Phys., 37, 2730 (2004).

[5] I. Muntele, P. Thevenard, C. Muntele, B. Chhay B, D. Ila. Mater. Res. Symp. Proc, 829, paper B.2.21 (2005).

[6] C. Li, Y. Yang, X. Sun, W. Lei, X. Zhang, B. Wang, J. Wang, B. Tay, J. Ye, G. Lo. Nanotechnology, 18, 135604 (2007).

[7] S.Chu, M. Olmedo, Zh. Yang, J. Kong, Z. Yang, J. Liu. Appl. Phys. Lett. 93, 181106 (2008).

[8] C. Li, G. Beirne, G. Kamita, G. Lakhwani, J. Wang, N. Greenham. J. Appl. Phys., 116, 114501 (2014).

[9] G.P. Smestad, M. Gratzel J. Chem. Educ., 75, 752 (1998).

[10] T. Tietze, P. Audehm, Y.-C. Chen, G. Schütz, B. Straumal, S. Protasova, A. Mazilkin, P. Straumal, T. Prokscha, H. Luetkens, Z. Salman, A. Suter, B. Baretzky, K. Fink, W. Wenzel, D. Danilov, E. Goering. Scientiv. Reps., 5: 8871, DOI: 10.1038/srep08871 (2015).

[11] J. Dodds, F. Meyers, K. Loh. Smart Struct. Syst., 12, 0.55 (2013).

[12] P. Chang. Digest J. Nanomater. Biostruct., 9, 777 (2014).

[13] C. Liu, H. Zhao, Y. Shen, G. Jia, J. Wang, Z. Mu. Nucl. Instrum. Meth. B, 326, 23 (2014).

[14] V. Privezentsev, V. Kulikauskas, A. Palagushkin, E. Steinman, A. Tereshchenko, A. Batrakov, S. Ksenich. Sol. St. Phenomena, 242, 369 (2016).

[15] V.V. Privezentsev, E.P. Kirilenko, A.N. Goryachev, A.V. Lutzau. Proc. 23th Intern. Symp. on Nanostructures (NANO 2015), (SPb Academic University, Russia) p. 49.

[16] A. Milnes. Deep Impurities in Semiconductors (Wiley, N.Y., 1973).

[17] The NIST $X$-ray Photoelectron Spectroscopy Database. Version 4.1. http://srdata.nist.gov/xps.

[18] Z. Jiang, R.A. Brown. Phys. Rev. Lett., 74, 2046 (1995). 


\section{Study of silicon implanted by zinc and annealed in oxygen}

V.V. Privezentsev ${ }^{1}$, E.P. Kirilenko², A.N. Goryachev' ${ }^{2}$, A.A. Batrakov ${ }^{3}$

${ }^{1}$ Institute of Physics \& Technology, Russian Academy of Sciences,

117218 Moscow, Russia

${ }^{2}$ National Research University "MIET", 124420 Moscow, Zelenograd, Russia

${ }^{3}$ National Research University „MPEl“, 111250 Moscow, Russia

Abstract The results of the study of the surface silicon layer and the formation of precipitates in samples $\mathrm{CZ} n$-Si $(100){ }^{64} \mathrm{Zn}^{+}$ions implanted with a dose of $5 \cdot 10^{16} \mathrm{~cm}^{-2}$ with an energy of $50 \mathrm{keV}$ at room temperature, followed by oxidation at temperatures from 400 up to $900^{\circ} \mathrm{C}$. Visualization of surface was carried by a scan electron microscope, and the surface layer depth profiling using mapping operation using scan Auger electron spectroscopy. Analysis of the impurity ion distribution in the silicon was carried out by a timeof-flight secondary-ion mass spectrometer. By $X$-ray photoelectron spectroscopy was studied the chemical state of silicon matrix atoms and of zinc and oxygen impurity atoms, as well as was refined phase composition of the implanted and annealed samples.

After implantation there are two maximum $\mathrm{Zn}$ concentration: on the plate surface and at a depth of $70 \mathrm{~nm}$, and on the sample surface and in the sample near-surface layer the nanoparticles of metal $\mathrm{Zn}$ phase and $\mathrm{ZnO}$ phase with size number of $10 \mathrm{~nm}$ were formed. After annealing in oxygen in Si near-surface layer $\mathrm{ZnO} \cdot \mathrm{Zn}_{2} \mathrm{SiO}_{4}$ phase was detected, and at depth of $50 \mathrm{~nm}$ the $\mathrm{Zn} \cdot \mathrm{ZnO}$ phase was detected. 